\title{
An unusual band causing intestinal obstruction: case report
}

\section{Suresh Chelliah$^{1}$, Sathia Dev Jayabalan², Meganathan Pachamuthu' ${ }^{1 *}$, Nimisha Puthiya Veettil ${ }^{1}$}

\begin{abstract}
${ }^{1}$ Department of Paediatrics, ${ }^{2}$ Department of Paediatric Surgery, Kauvery Hospital, Cantonment, Trichy, Tamil Nadu,
\end{abstract} India

Received: 13 September 2020

Revised: 12 November 2020

Accepted: 08 December 2020

\section{*Correspondence:}

Dr. Meganathan Pachamuthu,

E-mail: cloudking.hcl@gmail.com

Copyright: (c) the author(s), publisher and licensee Medip Academy. This is an open-access article distributed under the terms of the Creative Commons Attribution Non-Commercial License, which permits unrestricted non-commercial use, distribution, and reproduction in any medium, provided the original work is properly cited.

\begin{abstract}
We report an unusual case of intestinal obstruction. The child presented with intermittent abdominal pain. Initial USG abdomen and CT abdomen were inconclusive. Diagnostic laparoscopy followed by Laparotomy was done to remove bezoar made up of a rubber band and thread balls. Iron and zinc deficiencies are the preventable causes of pica. Plasticobezoars are rare and should be suspected when symptoms are not consistent with other common causes of obstruction.
\end{abstract}

Keywords: Intestinal obstruction, Plasticobezors, Bezoars, Laparoscopy

\section{INTRODUCTION}

Bezoars are intraluminal concretions of indigestible substances that form a rare cause of intestinal obstruction. They contribute up to $4 \%$ of small bowel obstruction. ${ }^{1}$

Bezoars are named according to the content. Lactobezoars (milk) are exclusively found in the newborns. Phytobezoars (vegetables) are found in the elderly. Trichobezoars (hair) are seen in the young. ${ }^{2}$ The term is derived from the Arabic word "badzehr" meaning antidote, since bezoars from animals were traditionally used in ancient times as cures for poison and even prized as precious stones. ${ }^{3}$ Plasticobezoars (plastics) are a rare cause of obstruction found in small children who ingest a variety of objects within their reach. ${ }^{4}$

\section{CASE REPORT}

We present an unusual case of a 3-year-old girl who presented to us with history of intermittent periumbilical abdominal pain for 2 months; severe in intensity and associated with poor feeding. She had an ultrasound abdomen taken 1 month earlier for similar complaints that was inconclusive. Resolved intussusception was suspected. Her neuropsychiatric development was normal.

Upon examination at our hospital, she was afebrile and vitally stable. Her abdomen was soft; there was a firm, ill-defined, tender mass palpable in the right lumbar region. Initially, mesenteric lymphadenopathy, Meckel's diverticulitis, recurrent intussusception were considered. She was treated with IV fluids, IV antibiotics and analgesics. Complete hemogram showed microcytic hypochromic anemia. Her ultrasound abdomen showed intraluminal hypoechoic tubular structure with hyper echoic wall within bowel loops. As the sonogram was not clear, CT abdomen was done. A short segment wall thickening in the ileum with probable foreign body like intra luminal lesion proximal to thickened loop was seen. Diagnostic laparoscopy followed by laparotomy was done. Intra operatively a bezoar made up of a rubber band and thread balls with features of partial intestinal obstruction was seen (Figure 1). Resection anastomoses of the involved segment was done. Histopathological 
examination of the specimen showed oedematous and necrotic ileal mucosa with chronic active inflammation. Her post-op period was uneventful. One unit of packed RBC was transfused. She was started on soft diet which she tolerated well and her symptoms gradually subsided. She was discharged on day 8. There were no episodes of abdominal pain after that and she is currently doing well.

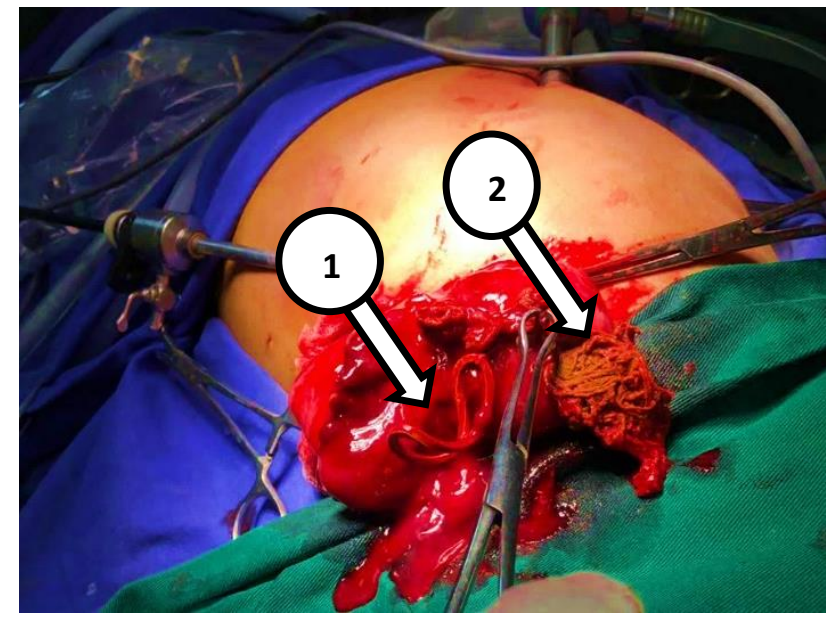

Figure 1: Intraoperative picture showing 1. rubber band 2 . bunch of thread.

\section{DISCUSSION}

Abdominal pain was the most common symptom followed by vomiting in children who have ingested foreign bodies. ${ }^{5} 10-20 \%$ will require intervention and less than $1 \%$ will require surgery when there is no obstruction. ${ }^{6}$ However bezaors that cause obstruction will need surgical intervention at times. Platicobezaors are common in older children and children with intellectual derangements. ${ }^{7,8}$ In our case this child is only three years old with history of PICA. Children with PICA commonly ingest dirt, stones, hair, ash, chalk etc. ${ }^{9}$ This may be case of accidental ingestion that was missed at that time.

Various methods have been used in managing children with intestinal obstruction caused by bezoars depending on the location. Bezoars in the small intestines are removed by laparoscopically or by open surgery. Colonic bezoars can be removed via rectal enemas or by manual evacuation under anaesthesia. If there is stricture or perforation of the bowel, resection and anastomosis is the management of choice. . $^{8-13}$

\section{CONCLUSION}

Iron and zinc deficiencies are the preventable causes of Pica. Plasticobezors though rare and should be suspected when symptoms are not consistent with other common causes of obstruction, especially in young children when there is anemia, PICA and history of unsupervised play or there is an intellectual derangement.

\section{ACKNOWLEDGEMENTS}

Sincere thanks to Dr. D. Senguttuvan, Executive Director, Kauvery Hospital, Trichy for constant motivation and support.

\section{Funding: No funding sources \\ Conflict of interest: None declared \\ Ethical approval: Not required}

\section{REFERENCES}

1. Oh SH, Namgung H, Park MH, Park DG. Bezoarinduced small bowel obstruction. J Kor Soc Coloproctol. 2012;28(2):89.

2. Kwok AM. Trichobezoar as a cause of pediatric acute small bowel obstruction. Clinic Case Rep. 2020;8(1): 166 .

3. Wang Z, Cao F, Liu D, Fang Y, Li F. The diagnosis and treatment of Rapunzel syndrome. Acta Radiol Open. 2016;5(11):2058460115627660

4. Botchway MT, Diakakis A, Westgarth-Taylor C. Obstructing colonic stricture due to intraluminal plastic foreign body. J Pediat Surg Case Rep. 2019;47:101236.

5. Diaconescu S, Gimiga N, Sarbu I, Stefanescu G, Olaru C, Ioniuc I, et al. Foreign bodies ingestion in children: experience of 61 cases in a pediatric gastroenterology unit from Romania. Gastroenterol Res Pract. 2016;2016.

6. Yadav RK, Yadav HK, Chandra A, Yadav S, Verma P, Shakya VK. Accidental aspiration/ingestion of foreign bodies in dentistry: A clinical and legal perspective. Nation J Maxillofac Surg. 2015;6(2):144.

7. Verma VK. Plastic bezoars - a unique introduction in bezoars family. Indian Journal of Surgery. 2013 Jun 1;75(1):51-3.

8. Yaka M, Ehirchiou A, Alkandry TT, Sair K. Huge plastic bezoar: a rare cause of gastrointestinal obstruction. Pan Afric Medic J. 2015;21(1).

9. Luby, Joan L, ed. Handbook of preschool mental health: development, disorders, and treatment. 2009.

10. Liu C, Deng H, Zhang Z, Bai L. Small bowel obstruction secondary to a mushroom bezoar: case report. Int J Gerontol. 2012;6(4):295-7.

11. Narayanan SK, Sherif VS, Babu PR, Nandakumar TK. Intestinal obstruction secondary to a colonic lithobezoar. J Pediat Surg. 2008;43(7):e9-10.

12. Miao D, Young SL, Golden CD. A meta-analysis of pica and micronutrient status. Am J Hum Biol. 2015;27(1):84-93.

13. Rose D, Dubensky L. Airway Foreign Bodies. In Stat Pearls. 2019.

Cite this article as: Chelliah S, Jayabalan SD, Pachamuthu M, Veettil NP. An unusual band causing intestinal obstruction: case report. Int J Contemp Pediatr 2021;8:177-8. 